\title{
EVOLUÇÃO DO PRONAF NO ESTADO DE GOIÁS: TENDÊNCIA DE CONCENTRAÇÃO DE INVESTIMENTOS EM ATIVIDADES PECUÁRIAS TRADICIONAIS
}

\author{
EVOLUCIÓN DEL PRONAF EN EL ESTADO DE GOIÁS: \\ TENDENCIA DE CONCENTRACIÓN DE INVERSIONES EN \\ ACTIVIDADES GANADERAS TRADICIONALES
}

DEVELOPMENTS OF PRONAF IN THE STATE OF GOIÁS: TREND OF CONCENTRATION IN TRADITIONAL LIVESTOCK FARMING

\author{
Graciella Corcioli - Universidade Federal de Goiás - Goiânia - Goiás - Brasil \\ graciellacor@gmail.com
}

\begin{abstract}
Resumo
0 artigo examina a aplicação do crédito do Programa Nacional de Fortalecimento da Agricultura Familiar (Pronaf) no estado de Goiás. Admite-se como hipótese o direcionamento desse recurso para atividades tradicionalmente financiadas pelo crédito rural e para municípios que apresentam maior dinamismo econômico. Dados coletados entre os anos de 2005 e 2017 revelam que o valor aplicado em Goiás aumentou sensivelmente, enquanto que o número de contratos caiu pela metade. Esse aspecto revela a concentração de recursos nas mãos dos agricultores que já acessam o Pronaf. Quanto à atividade financiada, foi possível identificar a aplicação prioritária em atividades pecuárias tradicionalmente financiadas. Os dez municípios que acessaram os maiores valores do Pronaf em Goiás, entre os anos de 2013 e 2017, tiveram o recurso aplicado principalmente na pecuária e, em determinados anos, alguns municípios acessaram apenas recurso pecuário. É possível concluir que a tendência à valorização das atividades produtivas tradicionais promovida pelo Pronaf tem como efeito incentivar a especialização produtiva entre os estabelecimentos da agricultura familiar, assim como foi feito durante o período da modernização conservadora da agricultura. Esse fenômeno, fomentado pelos próprios agentes mediadores da aplicação de recursos (sistema bancário e assistência técnica) acaba por excluir o público-alvo do programa. Em longo prazo este enfoque poderá contribuir para o processo de reconcentração fundiária no País.

Palavras-chave: Crédito Rural. Agricultura Familiar. Políticas Públicas. Política Agrícola.
\end{abstract}

\section{Resumen}

Este artículo examina la aplicación del crédito del Programa Nacional de Fortalecimiento de la Agricultura Familiar (Pronaf) en el Estado de Goiás. Se admite como hipótesis el direccionamiento de las inversiones para actividades tradicionalmente financiadas por el crédito rural y para municipios que presentan mayor dinamismo económico. Los datos recogidos entre los años 2005 y 2017 revelan que la suma invertida en Goiás aumentó sensiblemente, mientras que el número de contratos cayó a la mitad. Este fenómeno revela la concentración de recursos en manos de los agricultores que ya acceden al Pronaf. En cuanto a la actividad financiada, hubo aplicación prioritaria en actividades ganaderas tradicionalmente financiadas. Los diez municipios que accedieron a las mayores sumas del Pronaf en Goiás entre los años de 2013 y 2017 tuvieron el recurso aplicado principalmente en la ganadería $y$, en determinados años, algunos municipios accedieron apenas a recurso ganadero. Es posible concluir que la tendencia a la valorización de actividades productivas tradicionales impulsada por el Pronaf tiene como efecto incentivar la especialización productiva entre los agricultores familiares, así como pasó durante el período de la modernización conservadora de la agricultura. Este fenómeno, fomentado por los propios agentes mediadores de la aplicación de recursos (sistema bancario 
y asistencia técnica) acaba por excluir al público objetivo del programa. A largo plazo este enfoque podrá contribuir al proceso de reconcentración agraria en el país.

Palabras clave: Crédito Rural. Agricultura Campesina. Políticas Públicas. Política Agrícola.

\section{Abstract}

This paper assesses how the credits provided by the National Program to Strengthen Family Farming (Pronaf) have been applied in the State of Goiás. The research hypothesis is that funds are targeted at traditionally funded farming activities and channeled to municipalities with greater economic dynamism. Data collected between 2005 and 2017 reveal that the amount applied in Goiás increased considerably, while the number of contracts fell by half. This phenomenon reveals the concentration of resources in the hands of farmers who traditionally access Pronaf. As for the financed activity, there was a priority investment in traditionally financed livestock activities. The ten municipalities that accessed the highest mounts of Pronaf in Goiás between 2013 and 2017 invested mainly in livestock farming. In some years, some municipalities only accessed funds for investments in livestock. Pronaf's focus on traditional livestock activities encourages productive specialization among family farmers, as happened during the period of the conservative modernization of agriculture. This phenomenon, promoted by the governmental agencies implementing the program (both the banking system and the technical assistance agencies) ends up excluding the target audience of the Program. In the long term, this approach may contribute to the ongoing process of farm consolidation.

Keywords: Rural Credit. Family Farming. Public Policy. Agricultural Policy.

Introdução

O Programa Nacional de Fortalecimento da Agricultura Familiar (Pronaf) foi criado através do Decreto $\mathrm{n}^{0}$ 1.946, de 28 de julho de 1996 (Brasil, 1996), durante o governo do Presidente Fernando Henrique Cardoso (1995-2003). Desde então, o programa tem se firmado como a principal política pública do Governo Federal para apoiar os agricultores familiares. A partir de 1999, o Pronaf passou por novas reformulações e o tema da agricultura familiar ganhou mais espaço, tanto na esfera pública federal como em termos de visibilidade junto à sociedade civil.

O surgimento do Pronaf representou o reconhecimento e a legitimação, por parte do Estado, em relação aos agricultores familiares e, atualmente, o programa é o principal apoio econômico e produtivo da agricultura familiar (Schneider et al., 2004). É, portanto, uma política de extrema importância para o desenvolvimento rural (Gazolla; Schneider, 2013). Com o passar dos anos, o Pronaf foi se estruturando e, com isso, aumentou significativamente seu campo de atuação, além de ampliar os recursos, contratos e número de agricultores beneficiados. Uma importante etapa desse programa “ [...] foi a incorporação de novas linhas de crédito, com a inserção de mulheres, jovens, pescadores, indígenas e quilombolas, até então excluídos pelas políticas agrícolas" (Corcioli; Camargo, 2018, p. 255). Além da inserção de novas atividades agrícolas 
e não agrícolas no meio rural, como industrialização familiar, turismo rural, agrocombustíveis, entre outros (Brasil, 2003).

Todavia, mesmo sendo o principal programa de apoio à agricultura familiar brasileira, o Pronaf ainda enfrenta diversos desafios, principalmente quando se trata da capilaridade e da capacidade de desenvolver empreendimentos familiares rurais espalhados pelo Brasil. Nesse sentido, o Pronaf, apesar de ser um importante instrumento de promoção do desenvolvimento rural familiar brasileiro, nos moldes em que se encontra, ainda tende para uma perspectiva excludente e seletiva na medida em que os mecanismos e instituições de intermediação entre o recurso disponibilizado e o agricultor familiar modelam suas ações tendo como horizonte as condições de produção e distribuição de recursos próprias da agricultura de mercado.

\section{Distribuição do crédito Pronaf nas regiões brasileiras}

O Pronaf se consolidou como uma política de crédito presente em todo o território nacional, realizando em torno de dois milhões de contratos, atingindo mais de um milhão de famílias por ano safra, com uma carteira de 3,5 milhões de contratos ativos. Atualmente, o Pronaf é um programa de referência para o fortalecimento da agricultura familiar em todo o mundo (Bianchini, 2015).

Conforme indica a Figura 1, embora o valor do recurso disponibilizado pelo Plano Safra da Agricultura Familiar aumente a cada ano agrícola, o valor aplicado ficou sempre abaixo do valor disponibilizado, com exceção do Plano Safra 2013/14, e o número de contratos efetivados permaneceu quase inalterado, o que permite concluir que

[...] o número de agricultores familiares beneficiados com o PRONAF permanece o mesmo, aumentando, consequentemente, a concentração do recurso para uma parcela distinta de produtores familiares, possivelmente agricultores familiares mais desenvolvidos (Corcioli; Camargo, 2018, p. 269). 
Figura 1 - Evolução do Pronaf no Brasil (1999 a 2017)

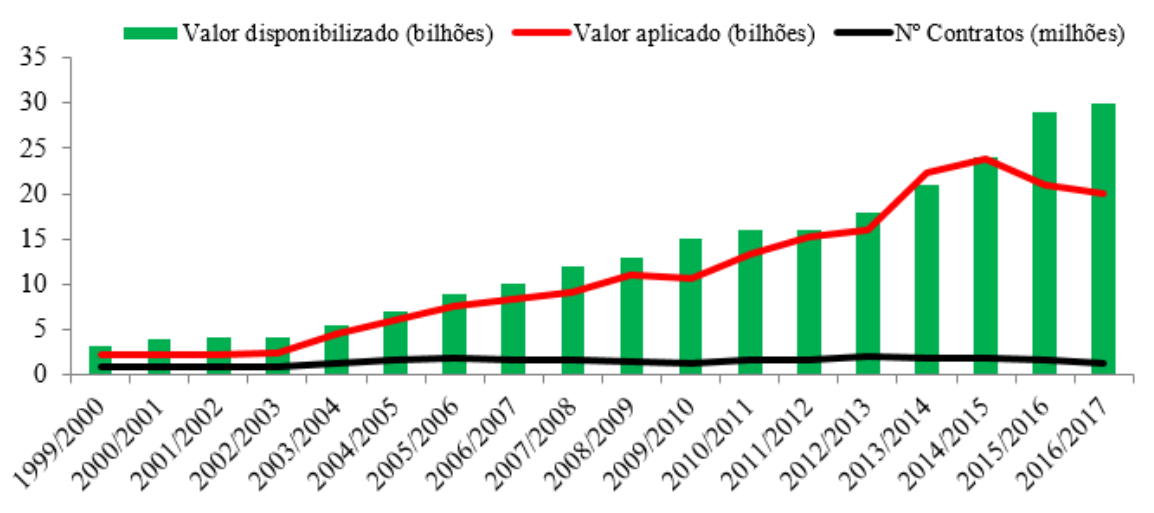

Fonte: Elaborado pelos autores com base em dados do Banco Central do Brasil (2018).

Essa tendência concentracionista tem como característica a regionalização dos acessos ao crédito, já que a maior parte dos recursos do Pronaf é acessada pelos estados do Rio Grande do Sul, Santa Catarina e Paraná (Gazolla; Schneider, 2013). Dados do Banco Central apontam que de 1999 a 2017 a Região Sul do Brasil acessou em média 51\% de todo recurso disponibilizado pelo Pronaf (Figura 2), o que na safra 2017/2018 representou um montante maior que $\mathrm{R} \$ 9$ bilhões do total aplicado em todo o país. Essa distribuição desigual dos recursos do Pronaf entre as regiões do Brasil fica mais evidente quando consideramos que 50\% dos agricultores familiares do país encontram-se no Nordeste, 19\% no Sul, 16\% no Sudeste, 10\% no Norte e 5\% no Centro-Oeste (Gazolla; Schneider, 2013). 
Figura 2 - Distribuição regional do valor total dos financiamentos do Pronaf

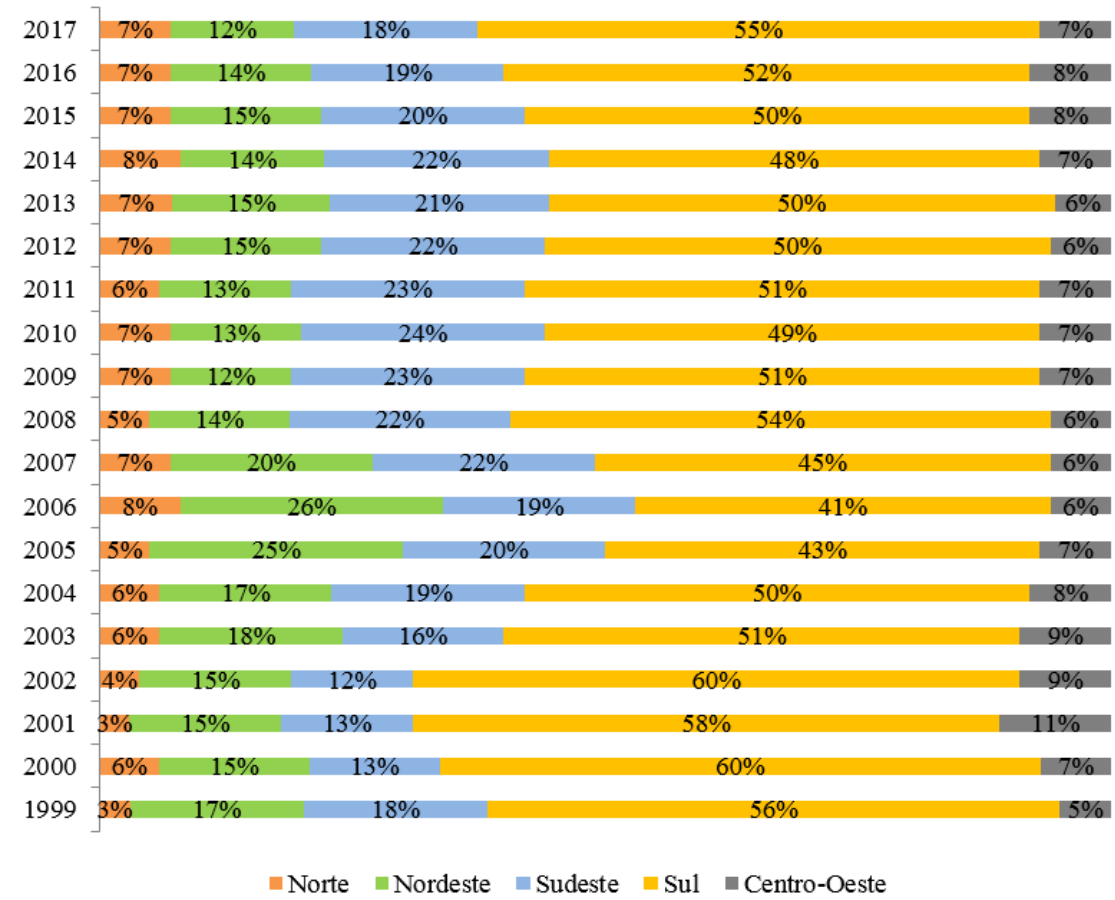

Fonte: Adaptado pelos autores com base em Silveira e Valadares (2014).

No ano de 2000, o percentual de municípios brasileiros que não acessavam o Pronaf era de $16,87 \%$, caindo para $10,79 \%$ no ano de 2004 , dado que representa uma melhor distribuição dos recursos do programa (Gasques et al., 2005). No entanto, nos anos seguintes, a distribuição dos financiamentos voltou a se concentrar principalmente na Região Sul do País (Souza et al., 2010). Segundo os autores, a retomada na concentração dos recursos do Pronaf está relacionada, provavelmente, às alterações nas normas do programa, que possibilitaram a inclusão de agricultores familiares mais capitalizados.

Até o ano de 2003, os agricultores familiares eram segmentados em quatro grupos de acesso ao Pronaf, sendo o Grupo A: assentados de reforma agrária; Grupo B: agricultores familiares de baixa renda; Grupo C: agricultores familiares com renda intermediária, e; Grupo D: agricultores familiares com estabilidade econômica. 
O teto de renda bruta anual para enquadramento no Grupo D, definido como o grupo de beneficiários de maior renda, era fixado em $\mathrm{R} \$ 27.500,00$ no período de 1997 a 2000, conforme a Resolução n ${ }^{0} 2409$, de 31 de julho de 1997. Com a criação do Grupo E na safra 2003/2004, esse teto subiu vertiginosamente, alcançando os $\mathrm{R} \$ 110.000,00$ na safra 2007/2008 (Aquino; Schneider, 2010). Em 2019, considera-se o limite de $\mathrm{R} \$ 415.000,00$ como renda bruta familiar máxima para enquadramento no Pronaf.

Para Aquino e Schneider (2010), essa alteração nas normas do programa facilita o acesso de agricultores mais capitalizados e com capacidade de oferecer aos agentes financeiros que mediam o acesso ao crédito, garantias mais efetivas que as faixas menos capitalizadas de agricultores familiares. Assim, os recursos financeiros são direcionados para agricultores mais capitalizados e para regiões mais favorecidas em detrimento de agricultores familiares mais fragilizados e regiões mais pobres, como é o caso do Nordeste.

Essa tendência também foi confirmada por Souza et al. (2013), que destacaram que até 2006 o crescimento na oferta de crédito esteve associado ao aumento do número de contratos, direcionados principalmente para agricultores do Nordeste, o que permitiu aumentar a participação dessa região no total dos recursos, contribuindo para reduzir a desigualdade na distribuição dos financiamentos. A partir de 2006, o volume de crédito voltou a se elevar nas regiões Sul e Sudeste, principalmente por dois motivos: aumento no número de contratos e aumento do valor médio dos contratos nessas regiões.

A Região Centro-Oeste acessa a segunda menor fatia do crédito do Pronaf, ficando à frente apenas da Região Norte (Figura 2). No entanto, de acordo com Souza et al. (2013), a partir de 2004 a Região CentroOeste passou a liderar o valor médio dos contratos de custeio, e as regiões Norte, Sul e Centro-Oeste têm, em geral, os maiores valores nos contratos de investimento (Souza et al., 2013). Esses dados indicam que o Pronaf, além de ser pouco distribuído na Região Centro-Oeste, está concentrado principalmente nos estabelecimentos mais capitalizados na medida em que o crédito para custeio atende a estabelecimentos rurais mais estruturados e já inseridos nas cadeias produtivas. 
Evolução do crédito Pronaf no estado de Goiás

Entre os anos de 2015 e 2017 os estados do Mato Grosso e Goiás acessaram, respectivamente, 51\% e 34\% dos recursos do Pronaf empenhados na região Centro-Oeste (BCB, 2018).

A agropecuária goiana se caracteriza pela grande produção de grãos, com destaque para o sorgo, o tomate e a cana-de-açúcar. Entre os estados produtores, Goiás se posiciona como o maior produtor de sorgo e tomate e o segundo maior produtor de cana-de-açúcar do país. Na pecuária, o estado de Goiás tem o segundo maior plantel bovino, com participação de $10,6 \%$ do rebanho nacional, e é o quarto maior produtor de leite do Brasil (IMB, 2018 a).

Em Goiás, boa parte dos recursos do Pronaf é destinada à pecuária (Figura 3), principalmente à bovinocultura de leite, por ser uma atividade bastante desenvolvida entre os agricultores familiares (Medina, 2018). O estado, assim como o país, segue "a tendência de aumentar o recurso aplicado nos contratos e manter o número de contratos efetivados quase que inalterado e, muitas vezes, decrescente" (Corcioli; Camargo, 2018, p. 271).

Oliveira et al. (2017) observaram que a pecuária se destacou representando 96,8\% de todos os recursos financiados pelo Pronaf em 2016. No ano de 2017, o total aplicado na pecuária foi da ordem de R 504 milhões, enquanto para a agricultura esse valor não alcançou os R $\$ 55$ milhões. Já em número de contratos, a pecuária efetivou aproximadamente 14 mil contratos, enquanto a agricultura efetivou pouco mais de mil contratos (Figura 3). 
Figura 3 - Evolução do Pronaf no Estado de Goiás (1995 a 2017)

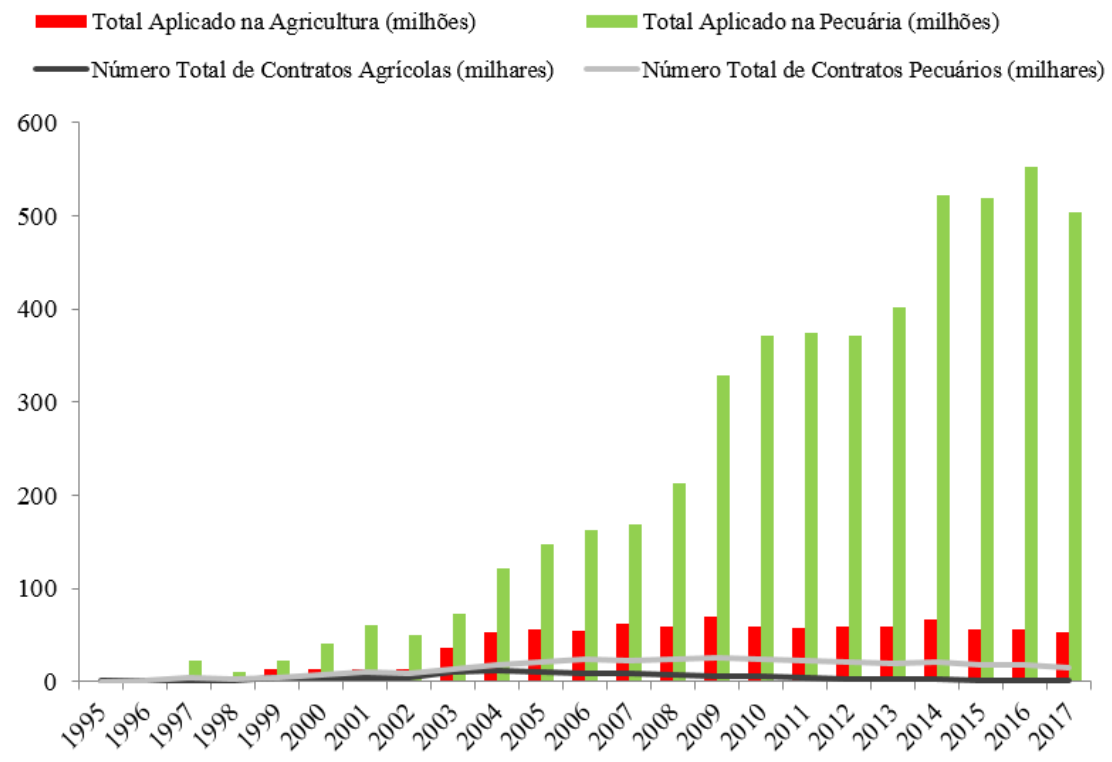

Fonte: Elaborado pelos autores com base em dados do Banco Central do Brasil (2018).

O valor aplicado em Goiás em 2005 foi maior que $\mathrm{R} \$ 200$ milhões e o número de contratos ultrapassou os 30 mil. Já em 2017, o valor aplicado ultrapassou os R $\$ 550$ milhões, o que representa um acréscimo de 275\%, enquanto que o número de contratos caiu pela metade (Figura 3). Esses números apontam a concentração de recursos nas mãos dos agricultores que tradicionalmente acessam o Pronaf. Esses agricultores muitas vezes têm maior facilidade na aquisição do crédito por conhecerem os caminhos para acessá-lo e por possuírem bom relacionamento com o agente financeiro.

A partir de 2011 é possível observar uma forte queda no número de contratos efetivados, de 25 mil em 2011 para 16 mil em 2017 (Figura 3). Esse decréscimo pode ser explicado pelo aumento na taxa de juros aplicados no crédito rural, que em 2011 não ultrapassava 4,5 \% a.a. e a partir de 2015 passou a 5,5 a.a., para a taxa máxima admitida no programa. Outro motivo possível diz respeito à crise que o país passou a enfrentar em decorrência da crise econômica mundial a partir de 2008. 
Atualmente, o crédito de custeio agrícola é praticamente inexiste na região Nordeste e é pouco utilizado nas regiões Norte, Centro-Oeste e Sudeste, com exceção de Minas Gerais (Bianchini, 2015). O estado de Goiás não foge à regra, conforme demonstra a Figura 4, a maior parte dos recursos de custeio são destinados à pecuária. O custeio agrícola é pouco utilizado e aponta característica decrescente a partir de 2008.

É importante observar também que o Seguro da Agricultura Familiar (Seaf) é adquirido exclusivamente via operação de custeio. Existe uma cobertura para auxiliar no pagamento de prestações de operações do Pronaf investimento e do Crédito Fundiário. Assim, além de acarretar uma série de prejuízos ao desenvolvimento das atividades rurais, "a inexistência de operações de custeio agrícola não permite que o Seaf faça a cobertura das operações de investimento restringindo o benefício aos agricultores familiares mais vulneráveis” (Corcioli; Camargo, 2018, p. 274).

Figura 4 - Evolução do Pronaf no Estado de Goiás: recursos aplicados na agricultura e pecuária e número de contratos efetivados por modalidade
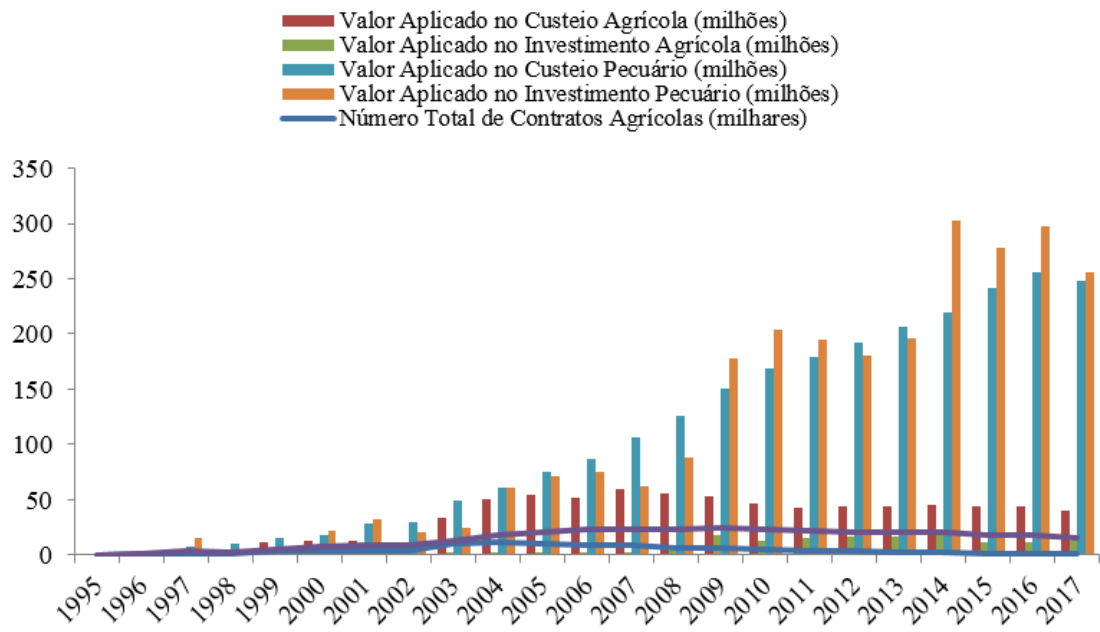

Fonte: Elaborado pelos autores com base em dados do Banco Central do Brasil (2018).

Existe também uma grande heterogeneidade no acesso ao Pronaf pelos municípios goianos. Oliveira et al. (2017 p. 539) destacam que as 
mesorregiões Centro e Sul do estado de Goiás recebem mais de 64\% dos recursos do Pronaf e, para os autores, "algumas unidades regionais da Emater-GO (Agência Goiana de Assistência Técnica, Extensão Rural e Pesquisa Agropecuária) chegam a elaborar até dez vezes mais projetos que outras". Não obstante, a cadeia de leite e produtos lácteos também se concentra no centro-sul do estado de Goiás (Castro et al., 2014).

A Figura 5 demonstra que os dez municípios que acessaram os maiores valores do Pronaf em Goiás entre os anos de 2013 a 2017 tiveram o recurso aplicado principalmente na pecuária.

Figura 5 - Valores e número de contratos do Pronaf acessados pelos primeiros dez municípios goianos que mais acessaram o Pronaf entre 2013 e 2017

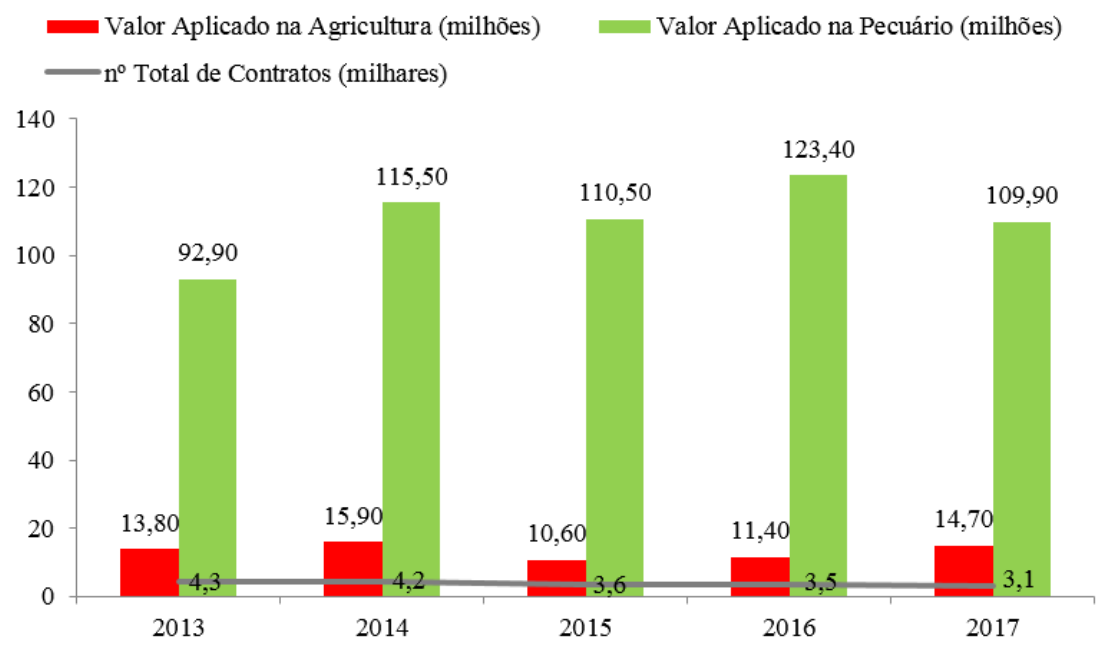

Fonte: Elaborado pelos autores com base em dados do Banco Central do Brasil (2018).

A Figura 6 apresenta a classificação dos dez municípios goianos que acessaram os maiores valores do Pronaf entre 2013 e 2017. Essa classificação se altera ano após ano, porém existe uma clara evidência de alguns municípios manterem suas posições, como é o caso de Orizona/ GO, que esteve em primeiro lugar em valor acessado e em número de contratos efetivados em todos os anos analisados. 
O município de Rio Verde/GO ficou na segunda posição em valor acessado em todos os anos analisados, exceto no ano de 2016 quando ocupou a sexta posição. Já a terceira posição foi disputada pelos munícipios de Itapuranga/GO, Morrinhos/GO, Pontalina/GO e Bela Vista de Goiás/ GO. Os dez municípios analisados acessaram mais recursos na atividade pecuária do que na atividade agrícola e, em determinados anos, alguns municípios acessaram apenas o recurso pecuário (Figura 6).

Figura 6 - Valores do Pronaf acessados por atividade pelos primeiros dez municípios goianos que mais acessaram o Pronaf entre 2013 e 2017

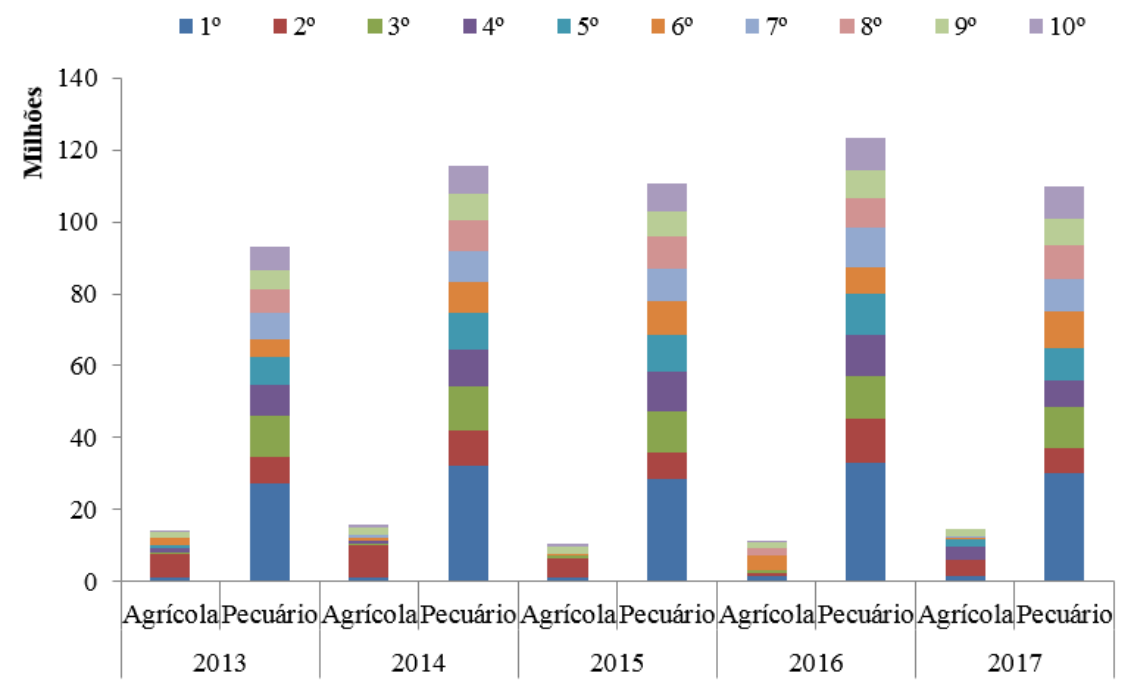

Fonte: Elaborado pelos autores com base em dados do Banco Central do Brasil (2018).

O maior acesso ao crédito pecuário do Pronaf se explica, em parte, pela produção leiteira de Goiás, com destaque para os municípios: Piracanjuba, Orizona, Jataí, Bela Vista de Goiás e Rio Verde, que ocupam, respectivamente, as cinco primeiras posições na produção de leite no estado, sendo que os três maiores produtores goianos figuram entre os 20 maiores produtores nacionais (IMB, 2018b).

A aplicação dos recursos do Pronaf em atividades tradicionais é explicada por três principais motivos. O primeiro é que “ [...] as instituições 
financeiras facilitam a liberação de recursos para financiar atividades já consolidadas na região, como é o caso da bovinocultura de leite em Goiás e das culturas de milho e soja nas regiões Centro-Oeste, Sul e Sudeste do Brasil” (Corcioli; Camargo, 2018, p. 273). No caso do estado de Goiás, a bovinocultura de leite passa a ser uma atividade de maior interesse dos agentes financeiros, pois os animais a serem adquiridos com o financiamento e os já existentes na propriedade se tornam ativos passíveis de serem utilizados como garantia do financiamento proposto. Reforça essa tendência a análise de Oliveira et al. (2017), na qual destacam que a Assistência Técnica e Extensão Rural (Ater) oferecida pela Emater-GO é mais demandada pelas atividades agropecuárias, que correspondem a 66\% dos atendimentos realizados. Destes atendimentos, $67 \%$ estão relacionados à atividade pecuária, sendo $73 \%$ para bovinocultura de leite e $26 \%$ para bovinocultura de corte.

O segundo motivo é que

o assessor técnico tem maior facilidade em elaborar projetos para financiar as atividades tradicionais, dada a facilidade em encontrar índices produtivos e tecnologias de produção que conferem ao projeto maior capacidade de pagamento e, consequentemente, maior possibilidade de aprovação. Vale ressaltar também que existe uma prática de aproveitar planilhas elaboradas para outros projetos. Ou seja, alguns técnicos utilizam projetos já elaborados e convencem o agricultor a desenvolver certa atividade simplesmente para facilitar a elaboração e aprovação do projeto. (Corcioli; Camargo, 2018, p. 273)

Ao longo de cinco anos de experiência de convívio com técnicos vinculados ao Programa de Assessoria Técnica, Social e Ambiental à Reforma Agrária (ATES), convivendo com profissionais da área de Agronomia, Veterinária e Zootecnia, em especial no município de Goiás, raros foram os profissionais que se empenharam na mudança do perfil produtivo das famílias rurais atendidas. Pelo contrário, entre 2004 e 2009, o perfil produtivo dos assentamentos rurais tornou-se mais especializado, voltando-se para bovinocultura de leite, indicando que a assessoria técnica implementada, ao invés de desenvolver o processo de diversificação e agregação de valor aos produtos locais, teve efeito contrário. Para Oliveira et al. (2017, p. 547), “a falta de assistência técnica ou a sua baixa qualidade influenciam negativamente na geração de renda pelos tomadores do Pronaf”. 
O terceiro e último motivo é que o próprio agricultor prefere financiar projetos para as atividades já consolidadas na região, dada a facilidade de acesso ao mercado consumidor, o que garante, teoricamente, recursos para a quitação do financiamento. Nas entrevistas realizadas com 144 agricultores familiares no Território Vale do Rio Vermelho, Medina (2018) observou tendência similar, com forte concentração na pecuária leiteira. Como argumentos apresentados pelos entrevistados, além de o produto já ter seu mercado consolidado, "há outros fatores que estimulam esse tipo de produção: a maior parte dos assentamentos do estado foi criada em fazendas com capim formado; a criação extensiva de gado tem manejo mais simples e demanda menos mão de obra” (MEDINA, 2018, p. 25).

Queiros et al. (2015) avaliam que a aplicação do recurso na atividade leiteira demonstra que o Pronaf está no caminho certo, pois a atividade assegura receita mensal ao agricultor, possibilitando o planejamento da gestão financeira e facilitando o pagamento da dívida adquirida com o financiamento. Certamente, considerando que a receita proveniente da atividade leiteira é mensal, a manutenção da bovinocultura de leite num estabelecimento da agricultura familiar é bastante adequada, porém, é preciso observar que a aplicação do recurso do Pronaf em apenas uma atividade contraria a perspectiva de diversificação própria da categoria, tendo efeitos danosos a médio e longo prazo.

\section{Avaliação do acesso ao Pronaf pelo público-alvo}

Avaliar a diferença na aplicação do recurso do Pronaf nas diferentes regiões do Brasil, nos leva a um questionamento: o baixo acesso ao Pronaf é explicado pelo modo limitado com que a categoria "agricultura familiar" é compreendida pelos agentes econômicos envolvidos na distribuição dos recursos? Devem ser considerados três aspectos fundamentais que nos levam a responder afirmativamente a essa pergunta.

Em termos de política de financiamento, dificilmente qualquer programa com abrangência em todo o território nacional conseguiria capturar a diversidade de modelos produtivos, contextos de produção e níveis de engajamento sociopolítico atualmente existentes no campo. Ora, uma política pública tão importante e abrangente como o Pronaf, embora tenha avançado muito nos últimos anos, precisa urgentemente ser revista de modo a contemplar a diversidade dos perfis culturais encontrados no campo brasileiro. Essa diversidade engloba principalmente aspectos: 
- Ambientais - o país tem dimensão continental, o que leva a uma diversidade ambiental muito expressiva que, consequentemente, interfere nas atividades rurais. Observe-se, por exemplo, a generalização da própria Lei $n^{\circ} 11.326$ de 24 de julho de 2006 (Brasil, 2006), que destina o Pronaf a "agricultores e produtores rurais que compõem as unidades familiares de produção rural”, pescadores artesanais, aquicultores, silvicultores (extrativistas artesanais, quilombolas, povos indígenas, "demais povos e comunidades tradicionais" desde que tenham, entre outros documentos a Declaração de Aptidão (DAP). De maneira extremamente equivocada, a relação orgânica existente entre atividades rurais e seus distintos ecossistemas é ignorada, tornando-os apenas uma paisagem, um espaço "culturalmente neutro", a partir do qual as atividades produtivas serão desenvolvidas.

- Socioeconômicos - considerando prioritariamente a desigualdade social encontrada entre as regiões do Brasil, já ressaltada por distintos indicadores como o IDH e Coeficiente de Gini, é possível afirmar que as regiões menos favorecidas (principalmente Norte e Nordeste) têm menor acesso às políticas públicas. No caso do IDH, indicadores como educação, longevidade e renda são estruturais para a composição desse indicador. Ao mesmo tempo, esses três fatores incidem diretamente sobre a capacidade dos trabalhadores do campo utilizarem os recursos disponíveis em suas propriedades. Estudos comprovam uma relação causal entre a dificuldade de adoção de tecnologia pela maioria dos produtores aos poucos investimentos em educação, principalmente nas regiões Norte, Nordeste e Centro-Oeste do Brasil (Schults, 1964; Alves, 2013). Em Goiás, no ano de 2016, mais de 70\% dos agricultores familiares não possuíam ensino médio completo e essa realidade representa um entrave na adoção do crédito do Pronaf. A desigualdade regional pode ser mitigada caso haja maior diversificação territorial na distribuição dos recursos do Pronaf (Oliveira et al., 2017).

- Culturais - a categoria designada como agricultura familiar engloba, além dos agricultores familiares tradicionais, extrativistas, quilombolas, pescadores, indígenas e beneficiários de reforma agrária. A pluralidade e diversidade cultural dessas comunidades apresentam diferentes demandas sociais e econômicas. A definição altamente genérica de agricultura familiar, que associa módulos fiscais variáveis e forma de trabalho é válida justamente porque permite a incorporação 
de distintos modos de produção, de vida e de conceber o vínculo com o produzido. A principal crítica feita ao processo de modernização da agricultura brasileira na década de 1960 foi a modulação impositiva, vertical e implementada por meio de pacotes tecnológicos indiferentes às experiências e padrões de vida e de produção pré-existentes. É justamente o mesmo erro que se observa no Pronaf atualmente.

Essas três condicionantes são suficientes para questionar o processo de implementação do Pronaf, em especial porque a relação de dependência com o mercado sempre foi tomada como uma condição inerente aos programas voltados para a agricultura, desde o governo de Fernando Henrique Cardoso (1995-2003). Tanto programas de acesso à terra, na forma de arrendamento ou compra, como de incrementação produtiva seguem essa tendência financista (Sauer; Pereira, 2006). Não sem razão, Mattei (2011, p. 9) aponta a possibilidade de a "modernização da agricultura familiar" levar à construção de um processo de produção de monoculturas tão excludente quanto a agricultura comercial tradicional propiciou em tempos anteriores. No que concerne à agricultura familiar, esse processo seria desastroso na medida em que tornaria o agricultor familiar de perfil menos empreendedor dependente das dinâmicas e políticas de preços de apenas um produto.

Deve-se considerar tais aspectos para aprimorar a referida política pública, a fim de torná-la mais apropriada e acessível ao público a quem se destina. Existem, por exemplo, regiões do Brasil em que o Pronaf deveria priorizar o financiamento de atividades de conservação ambiental, como ecoturismo e turismo rural, em detrimento das atividades produtivas que em muitos casos são inapropriadas (Corcioli; Camargo, 2018). Nesse sentido, o Brasil carece de estudos que apontem esses potenciais produtivos regionalizados, considerando atividades não agrícolas como geradoras de renda e passíveis de serem financiadas pelo Pronaf.

Lima e Vargas (2015), em trabalho realizado no município de Santa Cruz da Baixa Verde-PE, apontam que agricultores familiares passaram a desenvolver a agroecologia como alternativa ao modelo de agricultura convencional, criando a Associação de Desenvolvimento Rural Sustentável da Serra da Baixa Verde (Adessu Baixa Verde). Segundo os autores, existe "uma preocupação permanente em garantir a reprodução da unidade familiar pautada numa melhor qualidade de vida, em que se evidencia a 
presença de valores socioeconômicos, mas também o resgate de valores de cunho cultural e ambiental” (Lima; Vargas, 2015 p. 165).

Em termos de aplicação do recurso, ressalta-se a dificuldade de acesso ao Pronaf, imposta pelos agentes financeiros, evidenciada pela burocracia que se revela na exigência de documentos e na necessidade de assinaturas presenciais. Além da seleção adversa que, segundo Alves (2013), é promovida pelos agentes financeiros quando rejeitam agricultores que oferecem mais riscos às instituições bancárias privadas e raramente dão nova oportunidade a quem deixou de pagar uma prestação. Em outras palavras, um programa estatal de financiamento agrícola que deveria garantir o acesso a produtores que, em razão de sua própria definição teriam dificuldades de financiamento privado - corrigindo assim as distorções geradas pela própria lógica financista e mercadológicas das instituições bancárias - exclui seu público-alvo.

Aquino e Schneider (2010, p. 10) afirmam que:

De maneira geral, diferentes analistas observam que a distribuição desigual dos recursos do PRONAF está associada a problemas operacionais e sociopolíticos que estariam fora do raio de ação do programa. Assim, entre os fatores arrolados com maior frequência para explicar o quadro de desigualdades socioespaciais apresentado, destacam-se: os elevados obstáculos burocráticos impostos pelo sistema bancário aos agricultores familiares com níveis de renda inferiores; a maior organização dos agricultores mais capitalizados; as pressões de empresas agroindustriais às quais estes produtores estão vinculados; a concentração de agências bancárias e cooperativas de crédito nos estados da região Sul; e a desarticulação e baixa inserção social dos produtores do Norte e do Nordeste (Abramovay; Veiga, 1999; Bastos, 2006; Schröder; Souza, 2007, citados por Aquino; Schneider, 2010, p. 10).

Atualmente existem várias linhas de crédito para financiar uma diversidade de atividades na agricultura familiar, porém o recurso disponibilizado continua financiando atividades tradicionais, como milho, soja e bovinocultura de leite. A aplicação do recurso do programa no Brasil se comporta da seguinte maneira: 99,93\% do custeio agrícola é aplicado em lavouras, desses cerca de 50\% financiam apenas as lavouras de milho e soja; 97,83\% do custeio pecuário são alocados para animais; $52,7 \%$ do investimento agrícola se concentra na aquisição de máquinas e equipamentos, e; $57,7 \%$ do investimento pecuário se destina à aquisição de animais (Gazolla; Schneider, 2013). 
Para Oliveira et al. (2017, p. 529),

A política de crédito rural permitiu que os agricultores adquirissem os instrumentos necessários à dinamização da produção, contudo, essa aquisição foi seletiva e induziu a um processo de modernização desigual, privilegiando algumas atividades, tipo de produtores e regiões.

Diante dessas questões, os argumentos apresentados por Aquino e Schneider (2010) e Oliveira et al. (2017) são confirmados no estado de Goiás. O Pronaf apresenta um caráter seletivo e excludente fundamentado em um viés produtivista e setorial na medida em que sua versão recente elege os agricultores de maior renda como o seu público preferencial. Assim, a parcela mais significativa dos recursos se concentra nas mãos dos agricultores mais abastados e com maior nível de escolaridade, que são clientes preferenciais dos bancos, pois as normas de concessão dos créditos são aplicadas uniformemente em todo território nacional.

Azevedo e Pessôa (2011, p. 494) chamam a atenção para o "desvirtuamento da lógica do programa, ou seja, o emprego do recurso em fins não especificamente produtivos”. Em outras palavras, a valorização das atividades produtivas tradicionais promovida pelo Pronaf faz com que o programa acabe por fazer mais do mesmo, aprimorando os estabelecimentos da agricultura familiar assim como foi feito durante o período da modernização conservadora da agricultura. Algumas dessas atividades produtivas incentivadas pelo crédito do Pronaf, inclusive, reproduzem a utilização de pacotes tecnológicos, onde a maior parte do recurso é destinada para a aquisição de insumos de grandes empresas. Isto faz com que o agricultor, ao aplicar o crédito rural, assuma o risco do investimento, repassando para a grande empresa detentora das tecnologias a margem de lucro (Corcioli; Camargo, 2018).

Para Saron e Hespanhol (2012), a democratização do crédito rural, propiciada pelo Pronaf, é relativa, na medida em que prioriza financiamentos de acordo com o perfil do agricultor e o produto cultivado na região. Esse conjunto de restrições bloqueia o fortalecimento da agricultura familiar e mantém o agronegócio como prioridade para o desenvolvimento rural conduzido pelo Estado.

Por último, o assessor técnico tem papel central nesse sistema reprodutivo excludente na medida em que apresenta projetos que são bastante adequados para as instituições financeiras, mas não 
necessariamente para os agricultores familiares, contrariando a missão original do programa, voltada para a redução das desigualdades sociais e regionais, no intuito de reverter o quadro gerado por políticas governamentais conservadoras voltadas à modernização tecnológica da agricultura brasileira (Aquino; Schneider, 2010).

É importante que o assessor técnico, seja ele de instituição pública ou privada, tenha conhecimento técnico acerca de atividades não tradicionais que promovam a diversificação produtiva para a agricultura familiar, como por exemplo: silvicultura, piscicultura, horticultura, e de sistemas de produção diversificados, como: sistema agrosilvopastoril, sistema agroecológico, produção orgânica, entre outros. Além de conhecer e incentivar também as atividades não agrícolas, que, embora sejam contempladas, ainda são marginalizadas pelo Pronaf (Corcioli; Camargo, 2018).

Assim, é preciso inverter essa lógica verticalizada que orienta a política de distribuição de crédito do Pronaf, que fortalece as discrepâncias regionais, substituindo-a por uma perspectiva horizontalizada que, sem assistencialismos, democratize o acesso ao crédito, combata as desigualdades regionais e reduza a pobreza rural. Sem a superação desses impasses, diretamente associados às instituições que mediam o acesso ao crédito rural, o Pronaf dificilmente contribuirá com o combate ao processo de concentração fundiária no Brasil.

\section{Referências}

ALVES, A. Excluídos da modernização da agricultura: responsabilidade da extensão rural? Revista de Política Agrícola, n. 3, p. 3-6, jul./ago./set. 2013.

AQUINO, J. R.; Schneider, S. 12 anos da política de crédito do PRONAF no Brasil (1996-2008): uma reflexão crítica. In: CONGRESSO LATINO-AMERICANO DE SOCIOLOGIA RURAL, 8., 2010, Porto de Galinhas. Anais... Porto de Galinhas: ALASRU, 2010. p. 1-8.

AQUINO, J. R.; SCHNEIDER, S. (Des)caminhos da política de crédito do PRONAF na luta contra a Pobreza e a desigualdade Social no Brasil Rural. In: CONFERÊNCIA NACIONAL DE POLÍTICAS PÚBLICAS CONTRA A POBREZA E A DESIGUALDADE, 1., 2010, Natal. Anais... Natal: PPEUR, 2010. Acesso em: 19 nov. 2015.

AZEVEDO, F. F.; PESSÔA, V. L. S. O Programa Nacional de Fortalecimento da Agricultura Familiar no Brasil: uma análise sobre a distribuição regional e setorial dos recursos. Soc. \& Nat., Uberlândia, ano 23, n. 3, p. 483-496, set./dez. 2011. 
BCB. Banco Central do Brasil. 2018. Disponível em: < https://www.bcb.gov.br/ptbr/\#!/n/CREDRURAL $>$. Acesso em: 20 nov. 2018.

BIANCHINI, V. Vinte anos do PRONAF, 1995-2015: avanços e desafios. Brasília: SAF/MDA, 2015. 113 p.

BRASIL. Decreto $\mathrm{n}^{\circ}$ 1.946, de 28 de junho de 1996. Cria o Programa Nacional de Fortalecimento da Agricultura Familiar - PRONAF, e dá outras providencias. Disponível em: <http://www.planalto.gov.br/ccivil 03/decreto/D1946.htm>. Acesso em: 05 maio. 2019.

BRASIL. Lei $\mathrm{n}^{\circ} 11.326$ de 24 de julho de 2006. Altera dispositivos das Leis $\mathrm{n}^{\text {os }}$ 9.250, de 26 de dezembro de 1995, 8.212, de 24 de julho de 1991, 8.213, de 24 de julho de 1991, e 5.859, de 11 de dezembro de 1972; e revoga dispositivo da Lei $\mathrm{n}^{\circ}$ 605, de 5 de janeiro de 1949. Disponível em: <http://www.planalto.gov.br/ ccivil 03/Ato2004-2006/2006/Lei/L11324.htm>. Acesso em: 15 maio 2019.

BRASIL. Ministério do Desenvolvimento Agrário. Histórico do Pronaf. 2003. Disponível em: <http://www.mda.gov.br/portalmda/sites/default $>$. Acesso em: 23 nov. 2018.

CASTRO, M. de C.; LOPES, J. D.; SOUZA, R. G. de; SOUZA, C. B. de; NASCIMENTO, A. dos R. Cadeia Produtiva do Leite em Goiás: uma análise para o Território Estrada de Ferro. Conjuntura Econômica Goiana, n. 30, set. 2014. Disponível em: <http://wwwold.imb.go.gov.br/pub/conj/conj30/artigo 06.pdf>. Acesso em: 13 mar. 2019.

CORCIOLI, G.; CAMARGO, R. de S. Programa Nacional de Fortalecimento da Agricultura Familiar (Pronaf). In: MEDINA, G. da S. Agricultura familiar em Goiás: lições para o assessoramento técnico. 4. ed. Goiânia: UFG, 2018. 354 p.

GASQUES, J. G. et al. Agricultura familiar - PRONAF: análise de alguns indicadores. In: CONGRESSO DA SOCIEDADE BRASILEIRA DE ECONOMIA E SOCIOLOGIA RURAL, 43,. 2005, Ribeirão Preto. Anais... Ribeirão Preto: SOBER, 2005. p. 1-21.

GAZOLLA, M.; SCHNEIDER, S. Qual “fortalecimento" da agricultura familiar? Uma análise do Pronaf crédito de custeio e investimento no Rio Grande do Sul. Revista de Economia e Sociologia Rural, Piracicaba, v. 51, n. 1, p. 45-68, jan./ mar. 2013.

IMB. Instituto Mauro Borges de Estatísticas e Estudos Socioeconômicos. Síntese de Indicadores Socioeconômicos. Goiânia, 2018a. Disponível em: <http://www. imb.go.gov.br/index.php?option $=\mathrm{com}$ content $\&$ view $=$ article\&id $=88 \&$ catid $=28$ \&Itemid=216>. Acesso em: 13 mar. $20 \overline{19}$.

Análises estruturais, Goiânia, Ano XII, n. 6, out. 2018b. Disponível em: $<$ http://www.imb.go.gov.br/files/docs/releases/ppm/ppm2017.pdf $>$. Acesso em: 13 mar. 2019.

LIMA, F. A. X.; VARGAS, L. P. Alternativas socioeconômicas para os agricultores familiares: o papel de uma associação agroecológica. Rev. Ceres, Viçosa, v. 62, n.2, p. 159-166, mar.-abr. 2015. 
MATTEI, L. Evolução do crédito do PRONAF para as categorias de agricultores A e A/C entre 2000 e 2010. In: CONGRESSO DA SOCIEDADE BRASILEIRA DE ECONOMIA, ADMINISTRAÇÃO E SOCIOLOGIA RURAL, 49., 2011, Belo Horizonte. Anais... Belo Horizonte: SOBER, 2011.

MEDINA, G. da S. Agricultura familiar em Goiás: lições para o assessoramento técnico. 3. ed. Goiânia: Editora UFG, 2016. 288 p.

Agricultura familiar em Goiás: Lições para o assessoramento técnico. 4 èd. Goiânia: UFG, 2018. 354 p.

OLIVEIRA, G. R.; ARAÚJO, F. M. de; QUEIROZ, C. de. A importância da assistência técnica e extensão rural (ater) e do crédito rural para a agricultura familiar em Goiás. Boletim Goiano de Geografia, v. 37, n. 3, p. 528-551, set./dez. 2017.

QUEIROZ, G. J. de F.; LUNAS, D. A. L.; FRIAS, O. A. Análise do crédito do PRONAF no estado de Goiás no período de 2000-2011. RDSD, v. 1, n. 2, p. 05$26,2015$.

SARON, F. de A.; HESPANHOL, A. N. O Pronaf e as políticas de desenvolvimento rural no Brasil: o desafio da (re) construção das políticas de apoio a agricultura Familiar. Geo UERJ, ano 14, n. 23, v. 2, p. 656-683, 2012.

SAUER, S.; PEREIRA, J. M. M. Capturando a Terra: Banco Mundial, políticas fundiárias neoliberais e reforma agrária de mercado. São Paulo: Expressão Popular, 2006.

SCHNEIDER, S.; CAZELLA, A. A.; MATTEI, L. Histórico, caracterização e dinâmica recente do Pronaf - Programa Nacional de Fortalecimento da Agricultura Familiar. In: SCHNEIDER, S.; KUNRATH SILVA, M.; MORUZZI MARQUES, P. E. (Org.). Políticas públicas e participação social no Brasil rural. Porto Alegre: Editora UFRGS, 2004. 252 p.

SCHULTZ, T. W. Transforming traditional agriculture. New Haven and London: Yale University Press, 1964.

SILVEIRA, F. G.; VALADARES, A. A. Evolução recente do Pronaf-Crédito: 1999 a 2013. 2014. Disponível em: < http://www.redesrurais.org.br/6encontro/ trabalhos/Trabalho_290.pdf $>$. Acesso em: 23 mar. 2019.

SOUZA, P. M. de; NEY, M. G.; PONCIANO, N. J. Comportamento da distribuição dos financiamentos do Pronaf entre as unidades da federação, no período de período de 1999 a 2009. In: CONGRESSO DA SOCIEDADE BRASILEIRA DE ECONOMIA, ADMINISTRAÇÃO E SOCIOLOGIA RURAL, 48., 2010, Campo Grande. Anais.... Brasília: Sober, 2010.

SOUZA, P. M. de; PONCIANO, N. J.; NEY, M. G.; FORNAZIER, A. Análise da evolução do valor dos financiamentos do Pronaf-crédito (1999 a 2010): número, valor médio e localização geográfica dos contratos. Revista de Economia e Sociologia Rural, Piracicaba-SP, v. 51, n. 2, p. 237-254, abr/jun. 2013. 
Graciella Corcioli - Possui graduação, mestrado e doutorado em Agronomia pela Universidade Federal de Goiás. Atualmente é professora na Escola de Agronomia da Universidade Federal de Goiás. (iD https://orcid. org/0000-0002-3375-0700

Recebido para publicação em 13 de março de 2019 Aceito para publicação em 5 de maio de 2019 Publicado em XX de XXXX de 2019 